\title{
Comparison of the Effects of Topical Ebselen, Propolis and Steroid Applications of Acute Radiodermatitis: Preliminary Results
}

\author{
(ㄷ) Işı Akgün Demir1, (1) Selami Serhat Şirvan2, (1) Seyhan Hasçiçek3, (1) Canan Özdemir44, (1) Semra Karşıdağ² \\ 1University of Health Sciences Turkey, Gaziosmanpaşa Training and Research Hospital, Clinic of Plastic, Reconstructive and Aesthetic \\ Surgery, İstanbul, Turkey \\ 2University of Health Sciences Turkey, Şişli Hamidiye Etfal Training and Research Hospital, Clinic of Plastic, Reconstructive and Aesthetic \\ Surgery, İstanbul, Turkey \\ 3University of Health Sciences Turkey, Şişli Hamidiye Etfal Training and Research Hospital, Clinic of Pathology, İstanbul, Turkey \\ ${ }^{4}$ University of Health Sciences Turkey, Bağcılar Training and Research Hospital, Clinic of Radiation Oncology, İstanbul, Turkey
}

Cite this article as: Akgün Demir I, Şirvan SS, Hasçiçek S, Özdemir C, Karşıdağ S. Comparison of the Effects of Topical Ebselen, Propolis and Steroid Applications on Acute Radiodermatitis: Preliminary Results. J Acad Res Med 2021;11(1):11-16

\begin{abstract}
Objective: Radiodermatitis is one of the early complications of radiotherapy (RT). In an acute setting, skin changes may vary from mild hyperemia to necrosis. This study aimed to compare the effects of vaseline, mometasone furoate (MF), propolis and ebselen on acute radiodermatitis and demonstrate an alternative topical treatment method that could be suggested to reduce adverse effects.

Methods: A total of 40 male Wistar-Hannover rats were separated into 4 groups with 10 members to be applied with vaseline, steroid $(0.01 \%$ MF), propolis (30\%) and ebselen (1\%), respectively. All groups received radiation at a dose of 3,000 cGy. Following the application of RT, topical applications were applied to all groups and repeated once daily until the experiment was terminated. Skin biopsies were taken from all subjects and examined in terms of erosion, epidermis atrophy, basal layer degeneration, neovascularisation, polymorphonuclear leukocyte (PMNL) infiltration, loss of hair follicles and collagenisation.

Results: The level of erosion was found to be significantly lower in the MF group. Epidermal atrophy was statistically significant lower in propolis and vaseline groups. Propolis significantly decreased basal layer degeneration compared to other treatments. Neovascularisation rates were significantly higher in vaseline and ebselen groups. No significant difference was found between groups in terms of PMNL, loss of hair follicles and collagenisation.

Conclusion: Different agents with different mechanisms of action may be used according to the physiopathological progress of radiodermatitis. Data obtained in this study suggest that combined use of MF, propolis and ebselen according to erythema phases may mitigate the clinical progression of acute radiodermatitis.
\end{abstract}

Keywords: Ebselen, propolis, radiation dermatitis, steroid

ORCID IDs of the authors: I.A.D. 0000-0003-2047-9779; S.S.Ş. 0000-0003-4338-9610; S.H. 0000-0002-3243-8811; C.Ö. 0000-0002-7969-6746;

S.K. 0000-0003-2345-5000.

Corresponding Author/Sorumlu Yazar: Işıl Akgün Demir, E-mail: isilakgundemir@gmail.com
Received Date/Geliş Tarihi: 09.11.2020 Accepted Date/Kabul Tarihi: 13.12.2020

(C) Copyright 2021 by University of Health Sciences Turkey, Gaziosmanpaşa Training and Research Hospital. Available on-line at www.jarem.org 


\section{INTRODUCTION}

One of the early stage complications of radiotherapy (RT) is acute radiodermatitis. As a result of $R T$, various changes in the skin can be seen both short and long term. In acute period, these changes may be limited to simple hyperemia; however, this may progress to necrosis. In addition to deteriorated skin quality in the acute radiodermatitis, the quality of life of the patient can be seriously negatively affected by redness, pain and itching in this difficult period. Furthermore, the early termination of RT because of unhealthy skin tissue can cause the cancellation or postponement of potentially necessary surgical interventions, leading to treatment delay. There is no way to prevent formation of the acute radiodermatitis; however, various methods are applied to ameliorate the course.

Ebselen is a synthetic seleno-organic compound that shows similar activity to glutathione and thioredoxin peroxidase (1-3). Ebselen was designed to protect the skin from oxidative stress caused by ischaemia-reperfusion damage $(3,4)$. Previous studies have shown that ebselen inhibits radiation-origin apoptosis (3-5).

Propolis is a resinous material collected by bees from plant buds and exudates, mixed with bee enzymes, pollen and beeswax. It has been suggested that in addition to the anti-microbial and antioxidant properties of propolis, it also shows anti-inflammatory, anti-tumoral and immunomodulator activity (6).

This study aimed to evaluate vaseline, steroid [mometasone furoate (MF)], propolis and ebselen in respect of ameliorating or preventing acute radiodermatitis and compare their superiority.

\section{METHODS}

This study was approved by the Local Ethics Committee for Animal Studies of University of Health Sciences Turkey, Bağcılar Training and Research Hospital in April 2018 (approval number: 2018/47, approval date: 30.04.2018).

A total of 40 male Wistar-Hannover rats, weighing 200-300 gr each, were divided into 4 groups each to be applied with vaseline (control group), steroid (0.01\% MF) propolis (30\%) and ebselen $(1 \%)$, respectively.

On the first day of the experiment, all subjects were anaesthetised with $5 \mathrm{mg} / \mathrm{kg}$ xylazine and $50 \mathrm{mg} / \mathrm{kg}$ ketamine intraperitoneally, and the caudal dorsal region to which the RT and topical applications were to be applied was shaved.

All groups RT at a dose of 3,000 cGy using a Varian Clinac ${ }^{\circledR}$ IX Linear Accelerator, from a distance of $100 \mathrm{~cm}$, with the use of a 1.5 $\mathrm{cm}$ bolus with $6 \mathrm{mV}$ energy as a single fraction in service mode. RT was applied in a total of 5 sessions.

Following the application of RT, topical applications were applied to all groups and repeated once daily until the experiment was terminated on the $12^{\text {th }}$ day.

On day 1 after the application of RT, 2 rats died that were evaluated as anaesthesia-related complications. On days 3-4, rectitis developed in all groups. On day 4, 2 rats died and another 2 on day 6 , which was thought to be secondary to the development of severe rectitis despite fluid replacement. On day 12 , an additional of 2 rats died, yielding the total losses to 8 . The study was terminated although it had been planned to continue for 21 days.

\section{Histopathological Evaluation}

Skin and subcutaneous tissue biopsies were taken from all subjects. Following fixation in 10\% formaldehyde, samples were embedded in paraffin blocks, and then slices of 4 microns in thickness were obtained. Samples were stained with hematoxylin eosin, Masson trichrome and CD34, then examined under a light microscope and graded by a pathologist in respect of erosion, epidermis atrophy, basal layer degeneration, neovascularisation, polymorphonuclear leukocytes (PMNL) infiltration, loss of hair follicles and collagenisation parameters.

\section{Statistical Analysis}

Data obtained in the study were analysed statistically using the Statistical Package for the Social Sciences 24.0 software. Descriptive statistical methods were used, and results were stated as frequency, percentage, mean, standard deviation, median and interquartile range values. To compare erosion measurements between groups, the Kruskal-Wallis test was used. To compare other parameters between groups, the Pearson chi-square test was applied. Results were given in a $95 \%$ confidence interval. A value of $p<0.05$ was accepted as statistically significant.

\section{RESULTS}

\section{Macroscopic Findings}

Erythema was observed starting at a significant level in all subjects from the $3^{\text {rd }}$ day onwards. Hyperemia was most evident in the vaseline group (Figure 1). The finding of epilation was not evaluated macroscopically as the area applied with RT was shaved in all subjects so as to prevent topical applications inhibition. During the 12-day follow-up, no erosion, dry/wet desquamation or ulceration was observed macroscopically in any subject.

\section{Microscopic Findings}

\section{Erosion}

The level of erosion was 0 in all subjects in the steroid group, which was found to be significantly low compared to other groups. The difference between other groups was not determined to be statistically significant $(p>0.05)$.

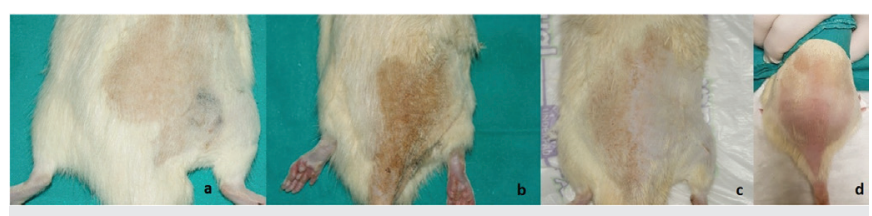

Figure 1. Rats on day 12 post-irradiation a) ebselen, b) propolis, c) steroid and d) vaseline 


\section{PMNL Infiltration, Hair Follicle Loss and Collagenisation}

No statistically significant difference was determined between groups in respect to these 3 parameters ( $p>0.05$ ).

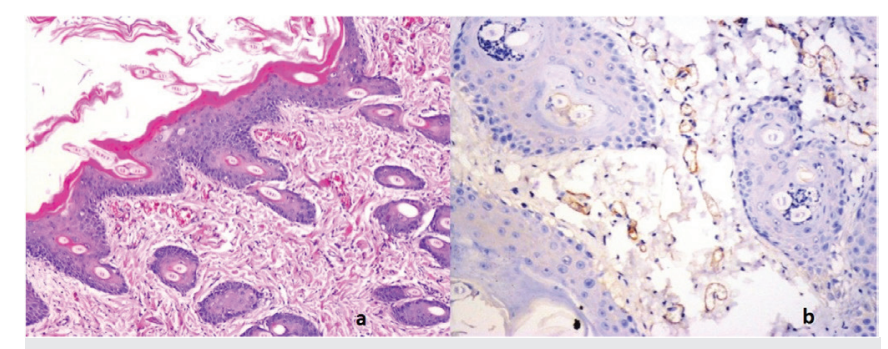

Figure 4. Significant proliferation of capillary structures in dermis in the ebselen group. a) hematoxyline and eosine $\times 200$ and b) CD31 200

\section{DISCUSSION}

Following the exposure to ionising radiation, double or single chain fractures occur in the nuclear and mitochondrial deoxyribonucleic acid (DNA) structure of cells, and free radicals are formed as a result of water molecules interaction within the cell (7-12). Free radicals inhibit synthesis of DNA causing further DNA damage, leading to structural changes of protein, lipid and carbohydrate molecules (10). The degree of radiation damage shows variations according to the total radiation dose, area of the body irradiated and tissue volume and frequency of application (9,12-14).

The first side-effect seen in the skin associated with RT is erythema, which can be classified in phases of early temporary erythema, primary erythema and late erythema. Early temporary erythema develops within hours of RT and is related to changes in vascular permeability $(11,15,16)$. Within $1-2$ days the early temporary erythema recedes, but more intense erythema may develop later (14). In this phase, the skin is hot and has a red and flaky appearance (16). The primary erythema reaction seen on approximately the $10^{\text {th }}$ day originates from the inflammation developing as a result from epithelial basal cell death. Late-stage erythema is seen between the $8^{\text {th }}$ and $10^{\text {th }}$ weeks as a result of dermal ischaemia and may give the skin a slight blue colour $(14,15)$.

Following the loss of basal cells in the epidermis, epidermal hypoplasia starts to develop within 3-5 weeks (15). Epilation and dry skin are observed as a result of reduced mitotic activity in the epidermis germinal cells, hair follicles and sebaceous glands $(10,11,16,17)$. In dry desquamation seen at the end of the $4^{\text {th }}$ week, changes in the skin are characterised by itching, flaking and increased melanin pigment in the basal layer causing a change in skin colour. With increased severity of hypoplasia due to radiation severity, age desquamation starts to be seen. The epidermis is completely lost in irradiated region and the dermis is exposed due to the opening of bullae which develop suprabasally in the irradiated region.
Figure 3. Basal layer degeneration at the epidermal-dermal junction (hematoxyline and eosine $\times 200$ ) 
Still, no gold standard treatment method is reported for radiodermatitis, and studies on this subject are on-going. According to the common view, the best method is the moisturisation of the irradiated region to prevent or minimise skin reactions (18). Methods reported in literature include washing with soap, use of deodorant, various lotions, aloe vera, calendula officinalis, biafine cream, hyaluronic acid/sodium hyaluronate cream, corticosteroids, sucralfate, antimicrobials, barrier films, various wound coverings, oral enzymes, pentoxifylline, colonystimulating factors, Vitamin $E$, prostaglandins, nitroxides, hyperbaric oxygen, thrombocyte-rich plasma, zinc sulphate, azelastine and captopril $(15,16,18-22)$. Various studies showed that corticosteroids are effective on an acute radiodermatitis table with an anti-inflammatory effect through various mechanisms such as vasoconstriction, capillary permeability and leukocyte proliferation and migration (23-25). Given the fact that moisturisation is the first and indispensable step in radiation dermatitis management, we designed the control group as the vaseline group with the aim of imitating this clinical scenario.

Unlike other rat model studies (21,26-28), the applied dose of radiation in the current study was determined as $30 \mathrm{~Gy}$. As a result of radiation applied with a linear accelerator providing a photon beam, 6 of the 40 rats in the current study were lost within 12 days because of diarrhoea which developed as a result of radiationrelated rectitis, thus, the experiment had to be terminated. In the planning of the study, the rectum mean dose of $3.4 \mathrm{~Gy}$ did not present any risk in respect to rectitis, hence, no problems were foreseen in using photon energy in the treatment (Figure 5). During the irradiation, some rats were observed to move as the anaesthesia effect had worn off. The inclusion of the rectum region in the radiation field is thought to be the reason for rectitis development. With this study, it was seen that failure of immobilization may lead to increased complication rate. In theory, RT application with photon beam energy was deemed for this study as appropriate. However, due to unforeseen conditions, such as failure of immobilization of the rats in this case, electron

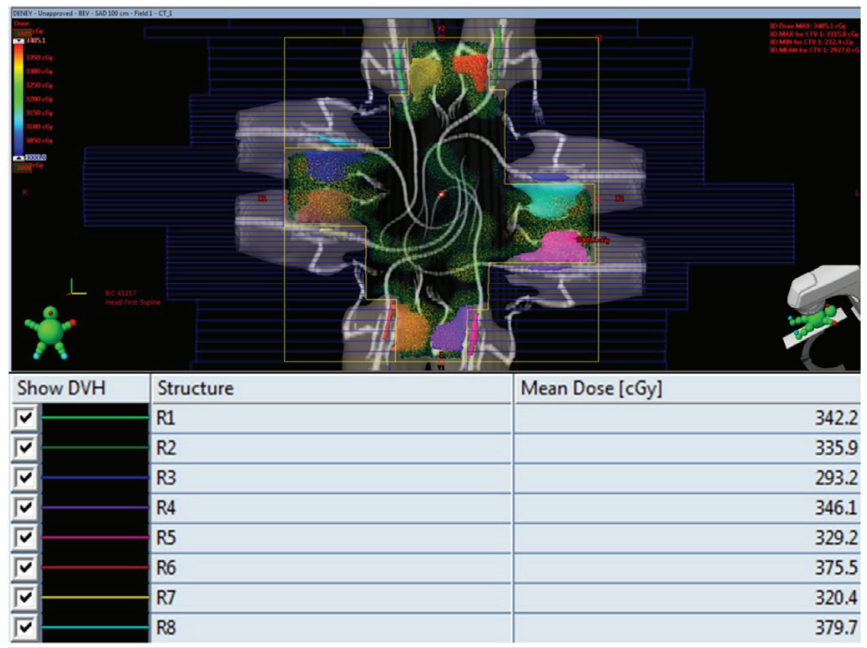

Figure 5. Distribution of radiation dose shaped with multi-leaf collimator on the irradiated target beam RT might be a safer option, since it has a lesser depth of penetration.

According to the study data, MF was seen to be superior in respect to preventing erosion development; however, it was not seen to make any positive contribution to epidermis atrophy, basal layer degeneration or neovascularisation. Steroids exhibit anti-inflammatory properties through various mechanisms such as vasoconstriction, capillary permeability, leukocyte proliferation and migration (23-25). These can be attributed to the effect of MF on erosion.

The only superiority of ebselen, which has antioxidant properties, over the application of propolis, steroid and vaseline, was its increasing neovascularisation effect. However, propolis was determined to have a positive effect on both epidermis atrophy and basal layer degeneration. We believe that ebselen may promote neovascularisation by reducing oxidative stress, vascular damaging factors and inflammation.

Propolis has also provided a biochemically available medium for re-epithelisation through its effects on collagen expression and degradation mechanisms (29). The anti-inflammatory and antioxidant properties of propolis may have played a role in reducing basal layer degeneration $(30,31)$.

No statistically significant difference was determined between groups in respect of PMNL infiltration, loss of hair follicles or collagenisation; however, when scores were examined separately, the collagenisation density was noticeable in the vaseline group (Figure 6).

To make a reliable evaluation of the effect of the agent used, agents applied in previous clinical studies in literature related to radiodermatitis have been used alone. Different effects observed on different agents in this study raised the idea of investigating the effect of combined treatments. In light to the preliminary data obtained, the application of different agents at different time interval and taking stages of radiodermatitis into consideration could be considered as an alternative treatment method in keeping the clinical course of radiodermatitis under control. As early erythema reaction is due to the increase in capillary permeability, corticosteroids may be useful in this phase due to their capillary permeability reducing effect. The primary

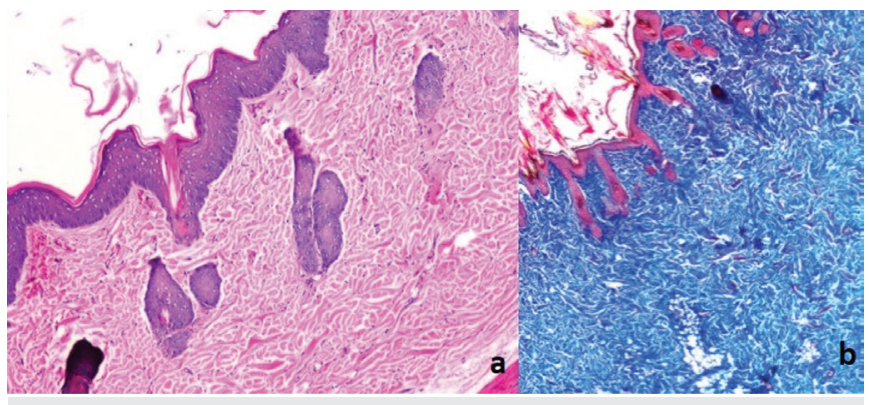

Figure 6. Collagen bundles extending from dermis to subcutaneous fat tissue. a) hematoxyline and eosine x200 and b) Masson Trichrome $\times 200$ 
erythema reaction that is seen with the loss of epithelial basal cells in the advanced stage can be brought under control by propolis, which has the property of preventing basal layer degeneration. When late-stage erythema is considered to be due to dermal vascular damage, after bringing the primary erythema reaction under control, changing the application to ebselen may be useful in minimising late erythema reaction with the increase in neovascularisation.

When optimum skin quality is maintained after taking all phases under control, the possibility of seeing more severe findings such as dry/wet desquamation, ulceration or necrosis can be further minimised. To the best of our knowledge, no previous study has been conducted on radiodermatitis neither with propolis or ebselen nor with photon linear accelerator. Therefore, a need for further experimental and clinical studies on the efficacy of the suggested alternative combined topical treatments to support findings of this study is recommended. The study by Kandaz et al. (32) is such an example.

\section{Study Limitations}

The most important limitation includes the termination of the study earlier as planned because the loss of $20 \%$ of subjects due to severe rectitis despite sufficient fluid replacement. Consequently, acute stage reactions were not observed over a sufficiently long period, and a suboptimal evaluation was made. Nevertheless, we had the chance to observe the main erythema reaction which occurred on the 10th day following RT. The range of RT models defined in animal studies in literature and complications encountered in those studies demonstrate the need for dosage to be studied on different devices. The short-term follow-up of radiation-related skin changes prevented the scoring of skin damage. In addition, the effect of treatments applied could only be evaluated in the short-term. However, we believe that preliminary results obtained from this study would contribute to the design of future studies.

\section{CONCLUSION}

The ability to protect the skin quality at the maximum level after $\mathrm{RT}$ is of the greatest importance in respect to patient comfort and treatment compliance, avoiding failure of the treatment process and reducing the complication rate of surgical procedures to be applied. Topical treatments in the prevention or treatment of radiodermatitis are more advantageous in terms of ease of application. Despite many experimental and clinical studies, no consensus has been provided on the point of prevention and treatment of radiodermatitis. Benefit can be gained from different mechanisms of different agents taking the physiopathological course of radiodermatitis into consideration. According to the preliminary data obtained, it can be predicted that according to erythema phases, the combined use of MF, propolis and ebselen could ameliorate the clinical course of acute radiodermatitis.

Ethics Committee Approval: This study was approved by the Local Ethics Committee for Animal Studies of University of Health Sciences Turkey,
Bağcılar Training and Research Hospital in April 2018 (approval number: 2018/47, approval date: 30.04.2018).

Informed Consent: This study is an animal experiment.

Peer-review: Externally peer-reviewed.

Author Contributions: Surgical and Medical Practices - I.A.D., S.S.Ş., S.H., C.Ö., S.K.; Concept - I.A.D., S.S.Ş., S.H., C.Ö., S.K.; Design - I.A.D., S.S.Ş., S.H., C.Ö., S.K.; Data Collection and/or Processing - I.A.D., S.S.S.., S.H., C.Ö., S.K.; Analysis and/or Interpretation - I.A.D., S.S.Ş., S.H., C.Ö., S.K.; Literature Search - I.A.D., S.S.Ş., S.H., C.Ö., S.K.; Writing - I.A.D., S.S.Ş., S.H., C.Ö., S.K.

Conflict of Interest: The authors have no conflict of interest to declare.

Financial Disclosure: The authors declared that this study has received no financial support.

\section{REFERENCES}

1. Parnham MJ, Leyck S, Graf E, Dowling EJ, Blake DR. The pharmacology of ebselen. Agents Actions 1991; 32: 4-9.

2. Sies H. Ebselen, a selenoorganic compound as glutathione peroxidase mimic. Free Radic Biol Med 1993; 14: 313-23.

3. Tak JK, Park JW. The use of ebselen for radioprotection in cultured cells and mice. Free Radic Biol Med 2009; 46: 1177-85.

4. Ramakrishnan N, Kalinich JF, McClain DE. Ebselen inhibition of apoptosis by reduction of peroxides. Biochem Pharmacol 1996; 51: 1443-51.

5. Sun J, Chen Y, Li MT, Zhou M, Ge ZL. Ebselen protects Chinese hamster ovary cells from radiation-induced apoptosis. Redox Rep 1997; 3: 153-7.

6. Sforcin JM. Biological properties and therapeutic applications of propolis. Phytother Res 2016; 30: 894-905.

7. Gianfaldoni S, Gianfaldoni R, Wollina U, Lotti J, Tchernev G, Lotti T. An overview on radiotherapy: from its history to its current applications in dermatology. Open Access Maced J Med Sci 2017; 5: 521-5.

8. Jang WH, Shim S, Wang T, Yoon Y, Jang W-S, Myung JK, et al. In vivo characterization of early-stage radiation skin injury in a mouse model by two-photon microscopy. Sci Rep 2016;6:19216. doi: 10.1038/srep19216.

9. Ryan JL. lonizing radiation: the good, the bad, and the ugly. J Invest Dermatol 2012; 132: 985-93.

10. Hymes SR, Storm EA, Fife C. Radiation dermatitis: clinical presentation, pathophysiology, and treatment 2006. J Am Acad Dermatol 2006; 54: 28-46.

11. Mendelsohn FA, Divino CM, Reis ED, Kerstein MD. Wound care after radiation therapy. Adv Skin Wound Care 2002; 15: 216-24.

12. Brown KR, Rzucidlo E. Acute and chronic radiation injury. J Vasc Surg 2011; 53: 15-21.

13. Ying $\mathrm{CH}$. Update of radiotherapy for skin cancer. Hong Kong $J$ Dermatology Venereol 2001; 9: 52-9.

14. Rifkin LH, Stojadinovic S, Stewart CH, Song KH, Maxted MC, Bell MH, et al. An athymic rat model of cutaneous radiation injury designed to study human tissue-based wound therapy. Radiat Oncol 2012; 7: 68.

15. ICRP, 2012. ICRP Statement on Tissue Reactions / Early and Late Effects of Radiation in Normal Tissues and Organs - Treshold Doses for Tissue Reactions in a Radiation Protection Context. ICRP Publication 118. Ann. ICRP 41(1/2). Available from: https://www.icrp.org/publication. asp?id=|CRP\%20Publication\%20118

16. McQuestion M. Evidence-based skin care management in radiation therapy: clinical update. Semin Oncol Nurs 2011; 27: 1-17.

17. Malkinson FD, Keane JT. Radiobiology of the skin: review of some effects on epidermis and hair. J Invest Dermatol 1981; 77: 133-8.

18. Salvo N, Barnes E, van Draanen J, Mitera G, Breen D, Giotis A, et al. Prophylaxis and management of acute radiation-induced skin reactions: a systematic review of the literature. Curr Oncol 2010; 17: 94-112.

19. Reinders Y, Felthaus O, Brockhoff G, Pohl F, Ahrens N, Prantl L, et al. Impact of platelet-rich plasma on viability and proliferation in wound healing processes after external radiation. Int J Mol Sci 2017; 18: 1819.

20. Ertekin MV, Koç M, Karslioğlu I, Sezen O, Taysi S, Bakan N. The effects of oral zinc sulphate during radiotherapy on anti-oxidant enzyme activities in patients with head and neck cancer: a prospective, randomised, placebo-controlled study. Int J Clin Pract 2004; 58: 662-8. 
21. Murakami R, Baba Y, Nishimura R, Furusawa M, Yokoyama T, Yamashita $Y$, et al. The effect of azelastine on acute radiation dermatitis in mice models. Int J Radiat Oncol Biol Phys 1997; 37: 907-11.

22. Ward WF, Molteni A, Ts'ao C, Hinz JM. The effect of Captopril on benign and malignant reactions in irradiated rat skin. Br J Radiol 1990; 63: 34954.

23. Boström A, Lindman $H$, Swartling $C$, Berne B, Bergh J. Potent corticosteroid cream (mometasone furoate) significantly reduces acute radiationdermatitis: results from a double-blind, randomized study. Radiother Oncol 2001; 59: 257-65.

24. Schmuth M, Wimmer MA, Hofer S, Sztankay A, Weinlich G, Linder DM, et al. Topical corticosteroid therapy for acute radiation dermatitis: a prospective, randomized, double-blind study. Br J Dermatol 2002; 146: 983-91.

25. Björnberg A, Hellgren L, Magnusson B, Mattsson I, Rosengren B. Topical treatment of radiation dermatitis with bethamethasone-17-valerate, vaseline and eucerine-a double-blind comparison. Clin Radiol 1967; 18: 463-4.

26. Ertekin MV, Tekin SB, Erdogan F, Karslioglu I, Gepdiremen A, Sezen O, et al. The effect of zinc sulphate in the prevention of radiation-induced dermatitis. J Radiat Res 2004; 45: 543-8.
27. Hebbar SA, Mitra AK, George KC, Verma NC. Caffeine ameliorates radiation-induced skin reactions in mice but does not influence tumour radiation response. J Radiol Prot 2002; 22: 63-9.

28. Chen YJ, Dai YS, Chen BF, Chang A, Chen HC, Lin YC, et al. The effect of tetrandrine and extracts of Centella asiatica on acute radiation dermatitis in rats. Biol Pharm Bull 1999; 22: 703-6.

29. Jacob A, Parolia A, Pau A, Davamani Amalraj F. The effects of Malaysian propolis and Brazilian red propolis on connective tissue fibroblasts in the wound healing process. BMC Complement Altern Med 2015; 15: 294.

30. Banskota AH, Tezuka Y, Kadota S. Recent progress in pharmacological research of propolis. Phytother Res 2001; 15:561-71.

31. Rossi A, Longo R, Russo A, Borrelli F, Sautebin L. The role of the phenethyl ester of caffeic acid (CAPE) in the inhibition of rat lung cyclooxygenase activity by propolis. Fitoterapia 2002; 73(Suppl 1):S30-7. doi: 10.1016/ s0367-326x(02)00188-0.

32. Kandaz M, Ertekin MV, Karslıoğlu I, Erdoğan F, Sezen O, Gepdiremen $A$, et al. Zinc sulfate and/or growth hormone administration for the prevention of radiation-induced dermatitis: a placebo-controlled rat model study. Biol Trace Elem Res 2017; 179: 110-6. 